\title{
Exploring the differential impacts of urban transit system on the spatial distribution of local and floating population in Beijing
}

\author{
ZHAO Meifeng ${ }^{1},{ }^{*}$ LIU Shenghe ${ }^{2,3}$, QI Wei ${ }^{2}$ \\ 1. College of Urban and Environmental Science, Tianjin Normal University, Tianjin 300387, China; \\ 2. Institute of Geographic Sciences and Nature Resources Research, CAS, Beijing 100101, China; \\ 3. College of Resources and Environment, University of Chinese Academy of Sciences, Beijing 1000, China
}

\begin{abstract}
The floating population has become the main driver of urban population excessive growth in China's mega cities. Urban transit system (UTS) is a significant factor in population spatial distributions within urban areas, especially rapid and high-capacity transit systems. This paper analyzes the causal effects of the extension of expressways and subways between 2000 and 2010 in the Beijing Metropolitan Area (BMA), focusing on the group differences between the local residents and the floating population. Due to the endogeneity of transportation improvements and population growth, Instrumental Variable (IV) regression model is applied to avoid this problem. The results show the local residents increased in the inner suburbs but decreased in the city center, while the floating population increased in the majority areas. IV regression results show that the extension of urban transit systems had statistically significant impacts on population growth across the BMA. The results also show that the extension of urban subway system had more effects on the floating population than the local residents across the BMA. It is mainly caused by the rather low fare of urban subway system. This implies that the excessive subsidy on urban subway system could result in excessive floating population growth and residential differentiation, even residential segregation. Hence, it is necessary to plan and design reasonable and scientific urban transit systems in order to advance reasonable population size and promote residential integration. Moreover, the regional analysis shows that the effects of urban transportation improvements on the local residents are not statistically significant in the inner suburbs. It implies that urban transportation improvements had limited effects on inducing people to move to suburban areas and controlling center city's population in Beijing. Therefore, it should be stressed the differentiated effects of urban transportation improvements on population distribution in the process of urban planning and population control.
\end{abstract}

Keywords: urban transit systems (UTS); population spatial distribution; causal effects; group differences; Beijing

Received: 2016-06-02 Accepted: 2016-12-06

Foundation: Key Project of National Natural Science Foundation of China, No.41230632, No.71433008; Doctoral Project of Tianjin Normal University, No.52XB1621

Author: Zhao Meifeng (1986-), PhD, specialized in urban geography. E-mail: zhaomeifeng@foxmail.com

*Corresponding author: Liu Shenghe (1967-), Professor, specialized in urban geography. E-mail: liush@igsnrr.ac.cn 


\section{Introduction}

The urbanization rate in China has been increasing at a high speed following the initiation of the domestic economic reforms in the 1980s, especially the initiation of market economy system in the 1990s. In 2012, 53.7\% of the total population lived in urban areas, and the urbanization rate is rising by approximately $1.3 \%$ every year. The urban population growth comes mainly from the massive influx of rural floating population into cities, especially in the megacities like Beijing and Shanghai. In 1978-2010, Beijing's floating population accounted for $62.61 \%$ of total population growth, with an increase at an average annual rate of $11.47 \%$ (4.5 times faster than for the total population) in Beijing. The floating population has become the main driver of urban population excessive growth in China's mega cities.

While the total population grows in the urban area, the spatial pattern of population is changing and exhibits group differences between the local residents (the people with local household registration) and the floating population (the migrants without local household registration) in China. Due to the institutional constraints of the hukou (household registration) system, floating population is not entitled to full citizenship rights as local residents, which lead to inequality in their housing inequality and residential differentiation in cities (Huang and Jiang, 2009; Wang et al., 2010; Wu, 2008). The floating population experiences many institutional restrictions associated with hukou system. They have very limited or no access to the housing-distribution system, state sector jobs, private cars, or the citywide welfare programs in Beijing. For instance, the floating population is required to demonstrate having paid into the Beijing personal income tax and social welfare pool for the previous five years to purchasing commodity housing or private vehicles. The floating population is excluded from access to Beijing housing guarantee policy (affordable or public housing). The majority of migrants are restricted to jobs that are desirable to the local population. Given these constraints, the floating population makes different housing choices and may have different residential distribution pattern. Previous studies suggest that local residents primarily reside in the city center, whereas the floating population is distributed mostly at the urban fringe. The spatial distribution of the floating population shows an outward shift ing tendency from the city center to the suburban areas, while the local residents exhibit a decentralization trend due to urban expansion and urban renewal (Wu, 2008; $\mathrm{He}, 2010)$.

In the determinants of population spatial redistribution within urban areas, urban transit system (UTS), especially rapid and high-capacity transit system, is a significant factor (Ma and Zhang, 2006; Qin and Du, 2000). UTS improvements accelerate the development of housing, office, retail and other amenities in urban areas alongside the new major roads because of the improvement of transportation accessibility. It would motivate people to relocate their residence from high-density inner city to low-density suburbs alongside the urban major roads (Zeng and Lin, 2005). Thus, transportation improvements are always viewed as a useful tool to induce urban population redistribution and urban spatial restructuring by designers and governments in China. Beijing municipal government proposes and pursues a transit-oriented development (TOD) policy to decrease population density in the city center. Due to the importance of urban transportation in population spatial distribution, the group differences between the local residents and the floating population on the effects of urban transportation improvements should be paid much more attentions. 
This paper analyzes the impact of UTS on the population spatial distribution and the group differences between the urban local residents and the urban floating population, taking the BMA as a case. To estimate the causal effects of urban transit improvements on the spatial distribution of population, we employ an instrumental variable (IV) estimation that uses natural experiments and transportation plans as instruments for the 2000-2010 changes in distance to the nearest expressway ramp and the distance to the nearest subway station. This paper proceeds as follows. In Section 2 we introduce the data source and the model of the relationship between UTS and population distribution based on urban land use theory. In Section 3 we analyze the change of population spatial distribution between 2000 and 2010 and UTS in the BMA. Section 4 is the IV regression results. It shows the extent to which the urban transit improvements had contributed to population growth of local residents and the floating population. In Section 5 we draw some conclusions.

\section{Theory and estimation}

\subsection{Urban land use theory}

The urban land use theory developed by Alonso (1964), Mills (1967) and Muth (1969) proposes a mechanism by which improvements in UTS may cause population redistribution. The classical monocentric city model assumes the city has only a single center, a central business district (CBD) that is the site of all business and commerce. In the model, population densities decline with distance from the city center, because people will pay a premium to avoid commutes to their jobs in the CBD (Arnott et al., 2008). Population densities decrease near the CBD and increase in the suburban areas when transit improvements increase commuting speeds. While the classical monocentric land use theory developed by Alonso (1964), Mills (1967) and Muth (1969) gave a reasonable mechanism through which transportation cost reduction may influence population spatial redistribution, it is still simplistic and crude. A large number of western scholars have made extensions to the baseline model presented above.

The first of these extensions regards modeling polycentric cities. Polycentric cities have emerged in many mega cities since the middle of 20th century due to employment dispersion (Meyer and Gómez-Ibáñez, 1981). Theories and models have been developed to analyze polycentric urban growth based on the concept of the polycentric city (Muller, 1981; Garreau, 1991; Veneri, 2010; Sweet et al., 2016).

The second of these extensions regards travel costs. Travel cost is not only in monetary term, but also in time cost. Anas and Moses (1979), Kim (2007), Baum-Snow (2007), Duranton et al. (2008), Garcia-López (2008), Kotavaara et al. (2011), more recently Chi (2012), considered competitions of different transportation infrastructures and incorporated radial commuting highways into the network of streets. Baum-Snow (2007) assessed the extent to which the construction of new limited access highways had contributed to central city population decline in the United States. He found that one new highway passing through a central city reduced its population by about 18\%. Garcia-López (2008) and Chi (2012) investigated the effect of transportation improvements on population changes and extended the finding of Baum-Snow (2007) at a much finer geographical scale. Kotavaara et al. (2011, 2012) and Calvo et al. (2013) paid more attention to the spatial varied impacts of urban 
transportation. Kotavaara et al. (2012) modelled the relationship between transport accessibility and population change and compared results using six different resolutions. The results showed that the relevance of modelled relationships was noted to be clearly dependent on geographical scale. Calvo et al. (2013) found that the impacts of Madrid subway on population settlement around new subway stations were greater in the outer areas.

The third of these extensions regards the heterogeneous resident characteristics. Residents have heterogeneous preferences of housing by demographic characteristics. Scholars proposed many urban land use models with a consideration of residents' heterogeneous income level and commuting costs (Beckmann, 1969; Starrs et al., 1989; Glaeser et al., 2008; Lau, 2011; Rogalsky, 2013; Preston et al., 2013). Starrs et al. (1989) stated that the public transport improved the mobility of the transport disadvantaged. Glaeser et al. (2008) found that the public transportation expansion raised the appeal of the city center to the poor in Atlanta, Portland, and Washington D.C. in the $1980 \mathrm{~s}$, because it eliminates the need to own a car in U.S. He states that poor residents would live in small dwellings close to the CBD, whereas rich residents should live in large house in the suburbs. Rogalsky (2013) focused on the unequal access to necessary transportation services of working-poor women.

Compared to the extensions in western research, the research in China concerns the extension of modeling polycentric cities and travel costs, but not the heterogeneous resident characteristics. Qin and Du (2000), Ma and Zhang (2006) and Zeng and Lin (2005) analyzed the relationship between urban transportation improvements and suburbanization in big cities of China. Ji et al. (2014) explored the interaction between urban transport and the distribution of population in Beijing. Wu et al. (2016) proposed a city expansion model to capture the coevolution relationship between population diffusion and road growth. In recent years, social-spatial differentiations occur in many big cities of China, such as Beijing (Feng and Zhou, 2008), Nanjing (Wu et al., 2013), Shanghai (Li and Wu, 2006). Not only the poor but also the floating population exhibit residential differentiation (Wang et al., 2010; Wu, 2008). With the constant increasing of the floating population in urban areas, the housing location and intra-city moving of the floating population were paid more and more attention. Liu (2015) found that migrant workers, who being the most marginalized group, have to move persistently as the city expands and modernizes itself. However, it is not clear of the differentiated casual effects of urban transportation improvement among varied social groups in China. The research in China provides almost no direct insights into the group differences concerning the impact of transit system on the population redistribution.

The study on the differentiated casual effects of urban transportation improvement between local residents and floating population has significant implications. From the theoretical aspects, it complements the urban land use theory with a consideration of Chinese institutional context. The previous western literatures pay much attention to heterogeneous resident characteristics in the urban transportation study. Western literatures mainly concern the different effects of urban transportation on the poor and the affluent. Due to institutional differences, there is not a social group in the western counties just like the floating population in China. As a unique social group in China, the floating population not only suffers from the socio-economic disadvantages as the poor, but also suffers from the institutional disadvantages. Our study focusing on the effects of urban transportation on the floating population could supplement the urban land use theory. From the practical aspects, it can 
assist the urban planner and management to optimally utilize the urban transportation when pursuing reasonable spatial redistribution of urban population. And it is also helpful to decrease residential segregation degree and improve social integration for the floating population.

\subsection{Estimated model}

Based on the classical monocentric land use model and its extensions on travel costs and polycentric cities, the effects of UTS on population density can be estimated by Equation (1) and Equation (2), respectively.

Based on the model, the effects of UTS on population density can be estimated by the following function (Clark, 1951; McDonald, 1989):

$$
\log P_{i}=\alpha_{m}+\beta_{m} d i s_{i}^{C B D}+\delta_{m} d i s_{i}^{t r a}+\varepsilon_{i}
$$

where $\log P_{i}$ is $\log$ population density for subdistrict $i$; $d i_{i}^{C B D}$ is the distance from the subdistrict $i$ centroid to CBD; $d i s_{i}^{\text {tra }}$ is the distance from the subdistrict $i$ centroid to the nearest transportation infrastructure; $\varepsilon$ is the error term.

Polycentric models allow the possibility of several main centers (Fujita and Ogawa, 1982; Anas and Kim, 1996; Wooldridge, 2009). The resulting spatial distribution of population follows a decreasing density pattern from the CBD and from the subcenters. In a polycentric city the effects of UTS on population density can be estimated by the following function:

$$
\log P_{i}=\alpha_{p}+\beta_{p} d i s_{i}^{C B D}+\delta_{p} d i i_{i}^{\text {sub }}+\gamma d i s_{i}^{\text {tra }}+\varepsilon_{i}
$$

where $\log P_{i}, d i s_{i}^{C B D}, d i s_{i}^{\text {tra }}$ and $\varepsilon$ are as described before; $d i s_{i}^{\text {sub }}$ is the distance from the subdistrict $i$ centroid to the nearest subcenter.

The BMA is characterized by the polycentric urban spatial structure (Feng et al., 2009; Sun, 2012). To study whether transit improvements affect changes of spatial distribution in the population, we estimate a first-difference specification base on Equation (2).

$$
\Delta\left(\log P_{i}\right)=\omega_{0}+\omega_{1} d i s_{i}^{C B D}+\omega_{2} d i s_{i}^{s u b}+\xi \Delta\left(\operatorname{dis}_{i}^{\text {tra }}\right)+\omega_{3} C_{i}+\varepsilon_{i}
$$

where $\log P_{i}, d i s_{i}^{C B D}, d i s_{i}^{\text {sub }}$, dis tra $_{i}^{\text {tra }}$ and $\varepsilon$ are as described before; $\Delta\left(\log P_{i}\right)$ represents the change of log population density for subdistrict $i$ during one period; $\Delta\left(\right.$ dis $\left._{i}^{\text {tra }}\right)$ represents the change of the distance from the subdistrict $i$ centroid to the nearest transportation infrastructure during one period; $\xi$ is a gradient and shows the extent to which the change of population density with the transportation improvements. $C$ represents the control variables, including initial population density.

As previous research points out, transportation improvements are expected to be endogenous to population growth. That is, transportation improvements could foster population growth in suburban areas while population growth in one place may increase the demand for transportation improvements and then stimulates the transportation construction. To deal with this issue, we apply IV regression to estimate the causal effects of transit system improvements on change of spatial distribution of population. IV regression allows consistent estimation when the model has endogenous explanatory variables. In this condition, ordinary linear regression (OLS) generally produces biased and inconsistent estimates (Imbens and Angrist, 1992; Yi, 2014). IV regression can eliminate simultaneous causality bias by an instrumental variable $(Z) . Z$ is uncorrelated with the error term $\varepsilon$ but is correlated with the endogenous explanatory variables. With this new variable, the IV estimator captures only the effects on the dependent variables of shifts in the endogenous explanatory variables induced 
by $Z$ whereas the OLS estimator captures not only the direct effects of the endogenous explanatory variables on the dependent variables but also the effect of endogeneity.

We use the Two Stage Least Squares (TSLS) to calculate IV estimates. Specifically, in the first stage we use all the exogenous covariates and the instruments $(Z)$ to predict the transportation improvements $\left(\Delta\left(d i s_{i}^{t r a}\right)\right)$. In the second stage, we use the predicted transportation improvements (rather than the original $\Delta\left(\right.$ dis $\left._{i}^{\text {tra }}\right)$ ) to predict the population density change. The TSLS estimation process is as follows.

Stage 1: Regress $\Delta\left(\right.$ dis $\left._{i}^{\text {tra }}\right)$ on all exogenous covariates and the instrumental variables $(Z)$ and compute $\Delta\left(\overline{\text { dis }_{i}^{\text {tra }}}\right)$ (Isolation of transportation improvements due to shifts in the population demand).

$$
\Delta\left(\text { dis }_{i}^{\text {tra }}\right)=\gamma_{0}+\gamma_{1} \text { dis }_{i}^{C B D}+\gamma_{2} d i s_{i}^{s u b}+\gamma_{3} \Delta Z_{i}+\gamma_{3} C_{i}+\mu_{i}
$$

where $Z_{i}$ is the exogenous instruments that have to satisfy the relevance, $\operatorname{cov}(Z$, $\left.\Delta\left(\operatorname{dis}_{i}^{\text {tra }}\right) \mid X\right) \neq 0$, and the exogeneity, $\operatorname{cov}(Z, \varepsilon)=0$.

Stage 2: Regress $\Delta\left(\log P_{i}\right)$ on $\Delta\left(\overline{\text { dis }_{i}^{\text {tra }}}\right)$.

$$
\Delta\left(\log P_{i}\right)=\omega_{0}+\omega_{1} d i s_{i}^{C B D}+\omega_{2} d i s_{i}^{s u b}+\xi \Delta\left(\overline{\text { dis }_{i}^{\text {tra }}}\right)+\omega_{3} C_{i}+\varepsilon_{i}
$$

where $\Delta\left(\overline{\text { dis }_{i}^{\text {tra }}}\right)$ is predicted changes in distance to transportation infrastructure as estimated in the first-stage.

\section{Data and model specification}

\subsection{Data}

The study area of our analysis is BMA. The BMA includes 12 districts of Beijing municipal administrative area, except for four districts of Huairou, Pinggu, Miyun and Yanqing. This definition and territorial scope of the BMA is drawn from Sun (1992), which is widely used in the BMA literatures (Feng et al., 2009; Sun et al., 2012). The BMA covers $9115 \mathrm{~km}^{2}$ of land, and in 2010 had a population of 18.01 million with a density of 1979 people per $\mathrm{km}^{2}$. Also in 2010 the floating population of 6.77 million accounted for $37.59 \%$ of the total population: one in every three people in the BMA was a member of the floating population. We divide the BMA into three zones based on the distance to the city center and 6th Ring Road that is a natural and recognized boundary of urban public transit systems in the BMA: city center, inner suburbs and outer suburbs (see Figure 1). The city center comprises Dongcheng District and Xicheng District. The inner suburbs are the subdistricts within the 6th Ring Road or passing through the 6th Ring Road. The outer suburbs are the remaining subdistricts. We use the subdistrict as our unit of observation that includes 226 subdistricts in the entire BMA. As the administrative boundaries of some subdistricts were rearranged in 2000-2010, it poses a problem for the population dynamic analysis at a subdistrict scale over time. We employ the merging method to resolve the problem. The merging method is a process of merging or incorporating the subdistricts, which were split, combined, or partially annexed to neighboring subdistricts in 2000-2010, into a set of new geographic units. The boundaries of this set of new geographic units could be held constant for the population from 2000 to 2010 . 
We use population data from the 2000 and 2010 Population Censuses. We categorize the population of the BMA into two groups: the local residents and the floating population. The local residents refer to those people who have Beijing hukou (household registration) and the floating population refers to the migrants from other provinces and without Beijing hukou.

Our transportation data is obtained from Beijing Travel and Transportation Map, satellite images in Google Earth and Beijing Urban Master Planning (2004-2010). The 2000 trans-

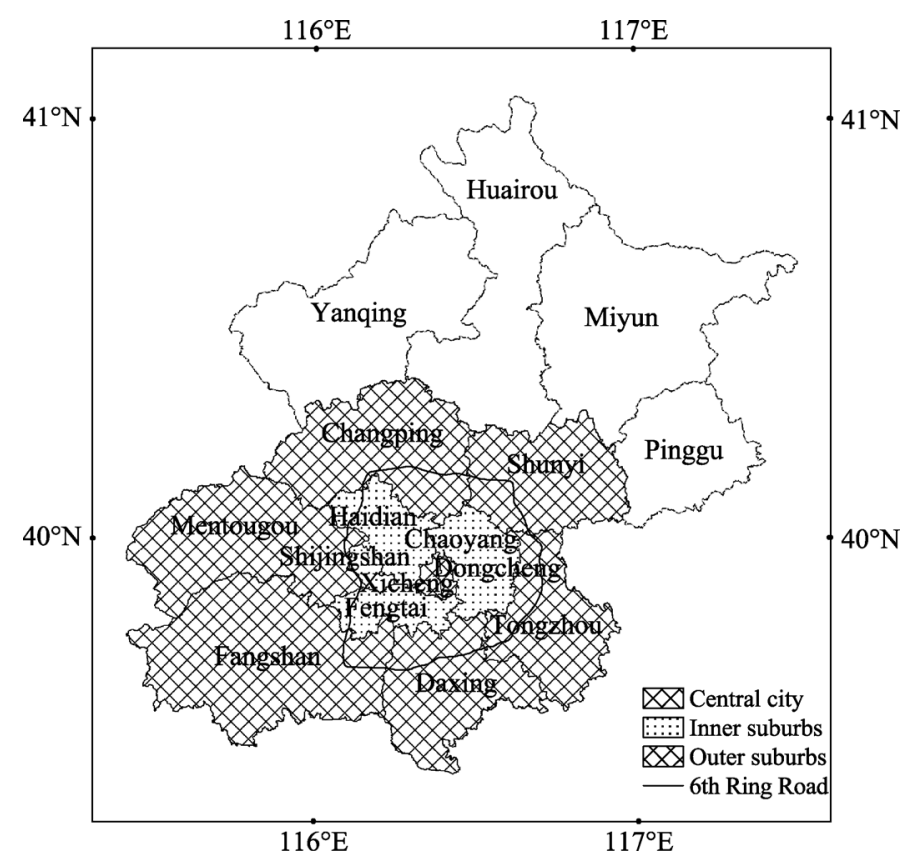

Figure 1 Geographical location of Beijing Metropolitan Area portation data is acquired by vectoring Beijing Travel and Transportation Map in 2000. The 2010 transportation data is the combination of the Beijing transportation map in Beijing Urban Master Planning (2004-2010) and satellite images in Google Earth (the images were obtained in 2010). We obtain the urban transportation spatial data for 2010 by vectorization.

\subsection{Model specification}

\subsubsection{Dependent variables}

Our analysis is related to three separate dependent variables. First, in order to assess the impacts of transportation improvements on the total population growth, we examine the 2000-2010 changes in $\log$ total population density, $\Delta\left(\log P_{2000-2010}\right)=\log P_{2010}-\log P_{2000}$. Second, in order to assess the group differences of the impacts of transportation improvements between the local residents and the floating population, we examine the 2000-2010 changes in log local resident density and the 2000-2010 changes in log floating population density, respectively.

\subsubsection{Independent and control variables}

As the urban land use theory and Beijing's population studies illustrated, the main variables related to urban population distribution are distance to employment center, travel cost and residential characteristics. Previous literatures on Beijing's population density also stated that Beijing's population spatial distribution were influenced mainly by employment opportunity, housing provision, transportation accessibility and individual characteristics such as income level, migration status and ownership of private vehicles (Qin and Du, 2000; Ma and Zhang, 2006; Feng et al., 2009; Banerjee et al., 2012). In this paper, we choose the distance to large employment center, transportation accessibility and the motorization rate as the explanatory variables. The migration status is also explored by constructing the model for local residents and the floating population 
respectively. We exclude housing provision and income levels from the control variables, which is based on our statistical analysis. We conduct OLS regression analysis in which the dependent variable is the change of log (total population density) in 2000-2010 and the independent variables include the average second-hand apartment listed prices, the number of rent apartments, the distance to $\mathrm{CBD}$, the distance to the nearest subcenter, the change of distance to the nearest expressway ramp, and the change of distance to the nearest subway station. The result shows that the average second-hand apartment listed prices and the number of rent apartments are both insignificant related to the BMA population change in 2000-2010 ( $>0.1)$. This result is contrary to previous research in which the housing provision is regarded as an important factor in the residential differentiation between local residents and floating population (Logan, 2008; Logan et al., 2009). We think this inconsistence between our study and previous research is the result of our imperfect housing data. Our housing data can only reflect the formal housing market but not the informal housing market which is an important housing source for the floating population. As the informal housing is illegal, the informal housing sale and rent transactions are conducted in private. Most property website, for example Soufun.com, Anjuke.com and Lianjia.com, and housing administration bureau cannot obtain the informal housing transaction data. Therefore, we should strive to mine the informal housing data and improve our analysis in the future study. Although our final estimated model does not include the housing provision, it is included in the error term and does not affect our results about the impact of urban transportation greatly. And we conduct correlational analysis to figure out the existence of multi-collinearity between the income level and the ownership of private vehicle. The results show that the average income is highly correlated to the private vehicle holding rate in the BMA $(\mathrm{p}<0.01)$. Thus, these unobserved variables would not significantly disturb and bias our results.

Due to the polycentric spatial structure of the BMA, we choose the distance to CBD and the distance to the nearest subcenter as the proxy to the distance to employment center. As for the travel cost, many Chinese studies stated that transportation accessibility was the main factor influencing urban population spatial distribution (Qin and Du, 2000; Zeng and Lin, 2005). The road network can be divided into three main parts: regular roads, expressways and subways in the BMA. In our study the urban transportation improvement just involves the latter two transit systems. In 2000-2010 Beijing transportation authority made great efforts on extension of rapid and high-capacity transportation infrastructures, such as subway systems and expressway systems; whereas, the regular road network was already highly dense, hence government's efforts were made on broadening and repairing it in the BMA. We conduct OLS regression analysis to verify whether or not the extension of urban regular road system is statistically significantly related to the population changes in the BMA. In this OLS regression model, the change of log (total population density) in 2000-2010 is regarded as the dependent variables, the change of urban regular road density is regarded as the explanatory variables, the distance to CBD, the distance to the nearest subcenter, and the change of distance to the nearest expressway ramp and the change of distance to the nearest subway station are regarded as the control variables. The results show that the change of urban regular road density is not statistically significantly associated with population density changes in the BMA (Table 1). Therefore, we choose the subway improvements and expressway improvements to measure the change of travel cost. The neglect of regular road network will not have many influences on the transportation accessibility improvement in 
the BMA. Considering the particularity of subways and expressways, which are only accessed by stations and ramps, we use the distance to the nearest subway station and the distance to the nearest expressway ramp to measure the transportation accessibility. The motorization rate, as an important demographic characteristic, may affect the effects of transportation accessibility, is included as a controlling variable. It is expected that expressway improvements should attract population residing in the areas with high motorization rate. Due to the data unavailability of motorization data by groups, we conduct preliminary quantitative analysis of the effects of motorization rate only for total population and discuss the possible effects by groups. The initial population density is also included as a controlling variable due to the agglomeration effects and the natural population growth.

Table 1 The regression results of urban regular road, 2000-2010

\begin{tabular}{llcc}
\hline \multicolumn{1}{c}{ Variables } & Variable description & Coefficient & P \\
\hline$\Delta\left(\right.$ dens $\left.^{\text {urr }}\right)$ & $2000-2010 \Delta\left[\right.$ urban regular road density] $\left(\mathrm{km} / \mathrm{km}^{2}\right)$ & 0.002 & 0.425 \\
$\Delta\left(\right.$ dis $\left.^{\text {exp }}\right)$ & $2000-2010 \Delta[$ distance to the nearest expressway ramp $](\mathrm{km})$ & -0.006 & 0.447 \\
$\Delta\left(\right.$ dis $\left.^{s w}\right)$ & $2000-2010 \Delta[$ distance to the nearest subway station $](\mathrm{km})$ & -0.029 & 0.001 \\
dis $^{C B D}$ & Distance to CBD $(\mathrm{km})$ & -0.008 & 0.001 \\
dis $^{\text {sub }}$ & Distance to the nearest subcenter $(\mathrm{km})$ & -0.003 & 0.555 \\
Constant & & 0.371 & 0.001 \\
R-squared & & 0.168 & 226 \\
Number of subdistricts & & 226 & 226 \\
\hline
\end{tabular}

The main explanatory variables include two types of urban transit improvements: expressway improvements and subway improvements. We construct expressway variable as the 2000-2010 changes in the distance to the nearest expressway ramp, $\Delta\left(\log \operatorname{dis}^{\exp } 2000-2010\right)=$ $\log$ dis $^{\exp }{ }_{2010}-\log$ dis $^{\text {exp }}{ }_{2000}$, and the subway variable as the 2000-2010 changes in the distance to the nearest subway station, $\Delta\left(\log d i s^{s w}{ }_{2000-2010}\right)=\log d i s^{s w}{ }_{2010}-\log d i s^{s w}{ }_{2000}$. These distances are computed as the straight-line distances. The geographical locations of CBD and the subcenters in the BMA are set as that in the finding of Sun et al. (2012). As the city center of Beijing is occupied by the Forbidden City, Beijing has developed two CBDs: one is Jinrong subdistrict located in the west of the Forbidden City; the other is Jianwai subdistrict located in the east of the Forbidden City. The subcenters of the BMA included Shangdi subdistrict, Zhongguancun subdistrict, Yayuncun, Gongzhufen, and Yingfeng subdistrict (location of Sinopec Beijing Yanshan Company), which are big urban business areas, hi-tech industrial parks, or large-size state-owned enterprises. To control for initial population density conditions, we use $\log 2000$ population density.

\subsubsection{Instrumental variables}

We choose the Euclidean spanning tree network and 1956 Beijing subway plan as our instrumental variables. We construct a hypothetical minimum spanning tree expressway network as instrument for actual expressway networks that are referred to as Euclidean spanning tree network. This instrument corresponds to the question of which expressway central planners would have been likely to construct if the sole policy objective had been to connect all targeted destinations on a single network in a least costly manner. In another words, Euclidean spanning tree network corresponds to the objectives of the expressway central planner: connecting Beijing and important cities in north China and minimizing global con- 
struction cost. To construct the Euclidean spanning tree network, the first step is to compute straight distances between all possible connections of the network, including Beijing, provincial capitals and other important cities in north China. We then compute Kruskal's algorithm to identify the minimum number of edges that connect all targeted destinations subject to the minimization of total network distance. As they were implemented with the aim of connecting Beijing and important cities in north China, the expressways happened to cross subdistricts which are located between Beijing city center and these important cities. Therefore, Euclidean spanning tree network is exogenous to population growth and socio-economic development of the BMA. Banerjee et al. (2012), Donaldson (2013) and Faber (2014) all used natural experiments to address the endogenous issue between transportation and economic growth. The validity of the 1956 Beijing subway plan as an instrument variable is based on the fact that this plan is the first subway plan in Beijing, and designed by the Central Government to facilitate military defense, not to facilitate the BMA development. Some scholars have used transportation plans as instrument variables of contemporary transportation, to evaluate their impacts on suburbanization (Baum-Snow, 2007; Garcia-López, 2012).

\section{Population spatial distribution and UTS in the Beijing Metropolitan Area}

\subsection{Change of population spatial distribution between 2000 and 2010}

Table 2 shows the change of the spatial distribution of the population in the BMA in 2000-2010. The total population growth came mainly from the inner suburbs. The total population of the inner suburbs accounted for $96 \%$ of the BMA's total population growth. Meanwhile, the total population growth of city center accounted for less than $1 \%$ of the total population growth of the BMA. There were also group differences in spatial distribution among the local residents and the floating population. It is remarkable that the local residents grew fastest in the inner suburbs while decreased in the city center. The floating population increased in every zone and the share of the floating population growth in the inner suburbs was $66.81 \%$ of the total population growth in the BMA.

Table 2 Population growth in different zones of different groups in Beijing Metropolitan Area, 2000-2010 (million)

\begin{tabular}{|c|c|c|c|c|c|c|}
\hline \multirow[b]{2}{*}{ Region } & \multicolumn{3}{|c|}{ Population in 2010} & \multicolumn{3}{|c|}{ Population growth in 2000-2010 } \\
\hline & $\begin{array}{c}\text { Total ( } \% \text { of total } \\
\text { population) }\end{array}$ & $\begin{array}{c}\text { Local residents } \\
\text { (\% of total } \\
\text { population) }\end{array}$ & $\begin{array}{l}\text { Floating popu- } \\
\text { lation ( } \% \text { of } \\
\text { total popula- } \\
\text { tion) }\end{array}$ & $\begin{array}{l}\text { Total }(\% \text { of } \\
\text { total population } \\
\text { growth })\end{array}$ & $\begin{array}{l}\text { Local residents } \\
\text { (\% of total popu- } \\
\text { lation growth) }\end{array}$ & $\begin{array}{l}\text { Floating popu- } \\
\text { lation (\% of } \\
\text { total population } \\
\text { growth) }\end{array}$ \\
\hline City center & $2.15(11.94 \%)$ & $1.59(8.83 \%)$ & $0.54(3.00 \%)$ & $0.06(0.94 \%)$ & $-0.20(-3.47 \%)$ & $0.26(4.39 \%)$ \\
\hline Inner suburbs & $13.99(77.68 \%)$ & $8.04(44.64 \%)$ & $5.82(32.32 \%)$ & $5.65(96.15 \%)$ & $1.68(28.62 \%)$ & $3.92(66.81 \%)$ \\
\hline Outer suburbs & $1.86(10.33 \%)$ & $1.44(8.00 \%)$ & $0.40(2.22 \%)$ & $0.17(2.9 \%)$ & $-0.06(-1.01 \%)$ & $0.23(3.96 \%)$ \\
\hline BMA & $18.01(100 \%)$ & $11.07(61.48 \%)$ & $6.77(37.57 \%)$ & $5.87(100 \%)$ & $1.42(24.14 \%)$ & $4.41(75.15 \%)$ \\
\hline
\end{tabular}

Figure 2 demonstrates the population spatial distribution in the BMA in 2000-2010. The total population density decreased in most subdistricts of the city center and in the western 
mountain areas of outer suburbs. Total population density increased in most subcenters except for Yingfeng subdistrict of Fangshan district where petrochemical industry was dominant. As Beijing municipal government made efforts on moving energyintensive, polluting businesses out of Beijing, the scale of the petrochemical industry is decreasing in recent years. Shangdi subcenter located in the northern inner suburbs attracted most people among all five subcenters. Shangdi subcenter is an electronic information industrial park, which experienced rapid development since the early 2000s. Total population density increased by the

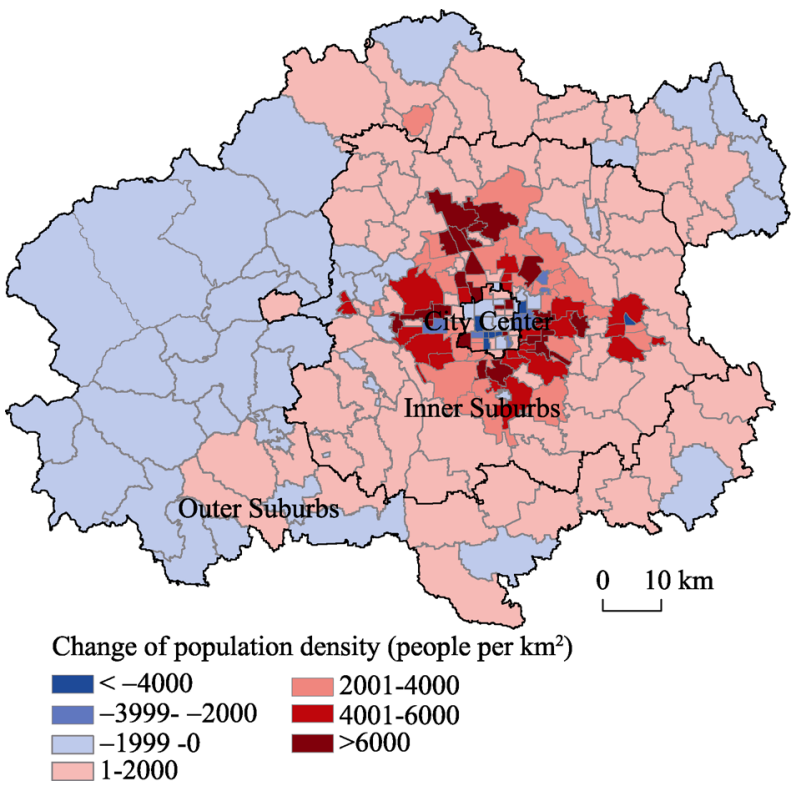

Figure 2 Changes of total population density of BMA at the subdistrict scale in 2000-2010 largest level in the inner suburbs encircling the city center which were always located large-scale residence communities, economic-technological development areas, and new satellite towns.

Figure 3 shows more explicitly the group differences of population growth in 2000-2010. The density of local residents showed a decreasing trend in the city center but an increasing trend in the inner suburbs. The local resident density decreased in Yingfeng subcenter but increased in other subcenters. This is because Yingfeng subcenter's dominant industry is state-owned petrochemical industry, which have no or little access to the floating population and whose employees are mostly accounted by the local residents. With the decreasing scale of the petrochemical industry, the local resident density showed accordingly a decreasing trend in the Yingfeng subcenter. However, the floating population density showed a totally different geographic pattern which increased in most subdistricts. Specifically, the local resident density decreased in a larger scale, including the city center, most subdistricts of the outer suburbs and the subdistricts of the inner suburbs that were far away from the city center. The local resident density increased by the largest level in the subdistricts of the northern and eastern inner suburbs. The change of the floating population density was totally different from the local residents. The floating population density increased in most subdistricts, except some subdistricts in western outer suburbs and several subdistricts in the city center. They increased by the largest level in the subdistricts of the inner suburbs which were about $12-17 \mathrm{~km}$ from the city center and exhibited a ring circling the city center.

\subsection{The UTS in Beijing Metropolitan Area}

The UTS in the BMA can be described as a combination of a chessboard pattern in the city center and a circular and radial pattern in suburban areas. The ring roads, radial expressways and subways are the arteries of these transit systems (see Figure 4). The First 


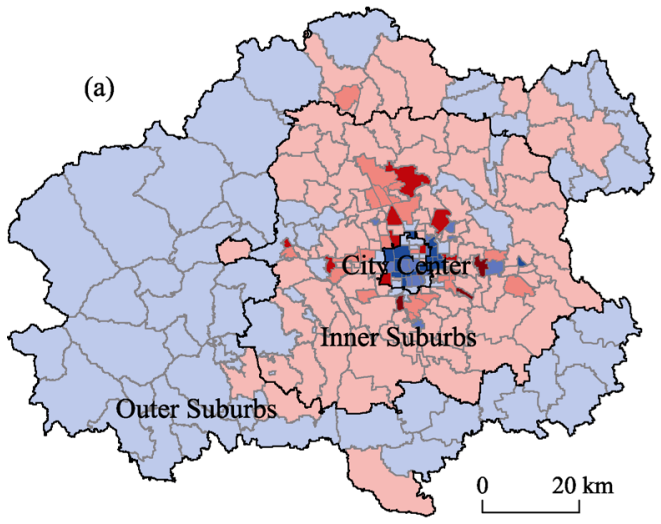

Changes of population density (people per $\mathrm{km}^{2}$ )

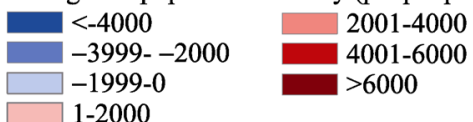

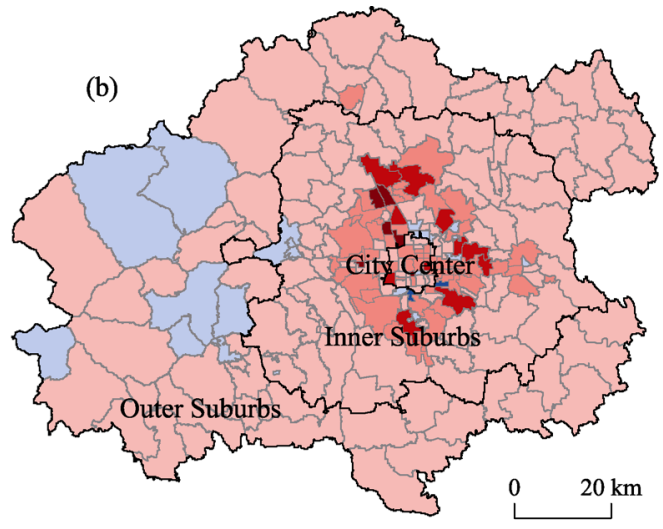

Changes of population density (people per $\mathrm{km}^{2}$ )

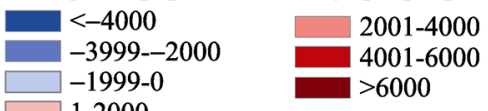

Figure 3 Population density changes of local residents and floating population of BMA at the subdistrict scale in 2000-2010: (a) Local residents; (b) Floating population

Ring Road circles the Forbidden City. All the other ring roads were constructed as urban areas expanded outwardly. In 2000 Beijing had four ring roads that were $172 \mathrm{~km}$ long with the 4th Ring Road serving as the boundary of the built-up area, which is approximately $8 \mathrm{~km}$ far away from the center of Beijing. In 2010 Beijing had six ring roads that were $543 \mathrm{~km}$ long, threefold the length as 2000. With the urban expansion, the 5th Ring Road became the edge of the built-up area that was roughly $17 \mathrm{~km}$ far away from central Beijing and the 6th Ring Road was designed as the regional transit road, a major truck road connecting other

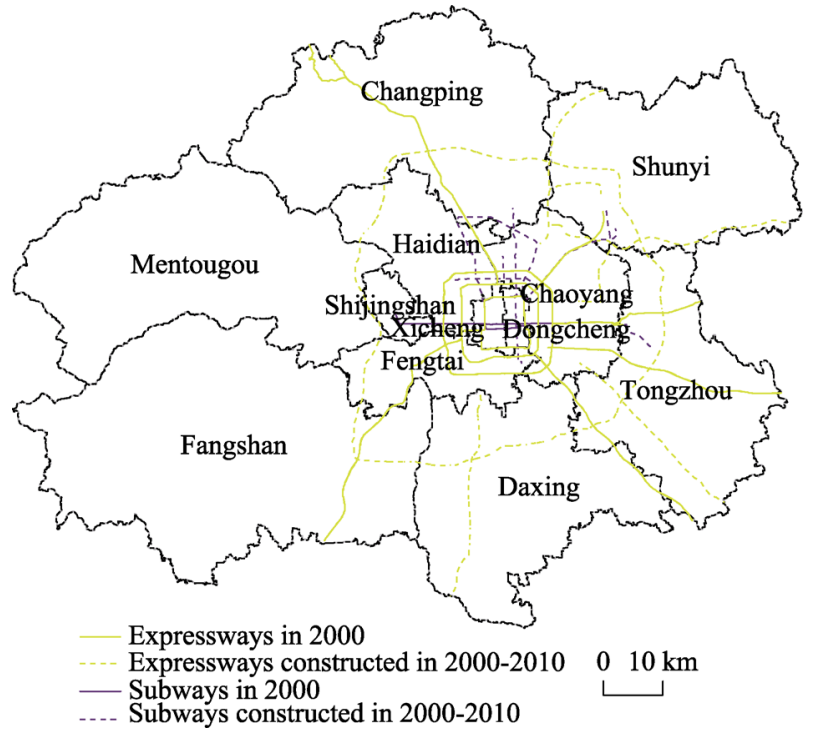

Figure 4 UTS of BMA in 2000 and new transportation improvements in 2000-2010 cities passing through the center of Beijing. The radial expressways link Beijing to its suburbs and other cities, providing rapid access between the ring roads and creating traffic corridors between Beijing and other cities. In 2010 Beijing had nine radial expressways with a total length of 357 $\mathrm{km}$, doubling that of 2000. In the early 2000s, after Beijing won its bid for the 2008 Olympic Games, the Beijing municipal government began to focus on extending the subway system. In 2000 the Beijing Subway only had 2 lines, $53 \mathrm{~km}$ of tracks and 39 stations; by the end of 2010 it has 8 lines, $194 \mathrm{~km}$ of tracks and 112 stations in operation. 


\section{The causal effects of transportation improvements on population redistribution in Beijing Metropolitan Area}

\subsection{Descriptive statistics}

There were 252 subdistricts in 2010 and 268 subdistricts in 2000 in the BMA. After we reorganize the administrative boundaries and design a set of new subdistricts whose boundaries are held constant in 2000-2010, there are 226 sample subdistricts in the BMA, 135 sample subdistricts in the inner suburbs, and 60 sample subdistricts in the outer suburbs. Table 3 presents descriptive statistics for the dependent, independent/control, and instrumental variables. In the entire BMA between 2000 and 2010 the average total growth of $\log$ population density was 0.27 , and the average growth of log floating population density was as high as 0.92 while the growth of log local resident density was only 0.07 . In the inner suburbs between 2000 and 2010 the average growth of $\log$ total population density was 0.47 , twice that as the entire BMA. In the outer suburbs between 2000 and 2010 the total population density exhibited a declining trend, with the average decline of log total population density as 0.02 . The key independent variables--reduction of distance to the nearest expressway ramp and reduction of distance to the nearest subway station--averaged $2.77 \mathrm{~km}$ and $4.50 \mathrm{~km}$ in the entire BMA, while in the inner suburbs they averaged $2.08 \mathrm{~km}$ and 4.35 $\mathrm{km}$ and they averaged the highest in the outer suburbs, with $5.72 \mathrm{~km}$ and $7.01 \mathrm{~km}$ respectively. The average motorization rate was $19.15 \%$ in the entire BMA, while it averaged $18.96 \%$ in the inner suburbs and it averaged the lowest in the outer suburbs $(16.22 \%)$.

Table 3 Summary statistics for main variables

\begin{tabular}{|c|c|c|c|c|c|c|c|}
\hline \multirow{2}{*}{ Variables } & \multirow{2}{*}{ Variable description } & \multicolumn{2}{|c|}{ Entire BMA } & \multicolumn{2}{|c|}{ Inner suburbs } & \multicolumn{2}{|c|}{ Outer suburbs } \\
\hline & & Mean & S.D. & Mean & S.D. & Mean & S.D. \\
\hline \multicolumn{8}{|c|}{ Dependent variables } \\
\hline$\Delta(\log T P)$ & $2000-2010 \triangle[\log ($ total population density) $]$ & 0.271 & 0.470 & 0.465 & 0.474 & -0.024 & 0.292 \\
\hline$\Delta(\log L R)$ & $2000-2010 \triangle[\log ($ local resident density $)]$ & 0.065 & 0.400 & 0.200 & 0.429 & -0.125 & 0.228 \\
\hline$\Delta(\log F P)$ & $2000-2010 \triangle[\log ($ floating population density) $]$ & 0.916 & 0.700 & 1.077 & 0.632 & 0.714 & 0.864 \\
\hline \multicolumn{8}{|c|}{ Independent and control variables } \\
\hline$\Delta\left(\operatorname{dis}^{\exp }\right)$ & $2000-2010 \triangle$ distance to the nearest expreeway ramp $](\mathrm{km})$ & -2.767 & 4.675 & -2.083 & 3.383 & -5.715 & 6.600 \\
\hline$\Delta\left(d i s^{s w}\right)$ & $2000-2010 \triangle$ [distance to the nearest subway station] $(\mathrm{km})$ & -4.497 & 5.805 & -4.354 & 4.996 & -7.006 & 7.468 \\
\hline$d i s^{C B D}$ & Distance to CBD $(\mathrm{km})$ & 20.639 & 16.401 & 14.561 & 8.383 & 43.148 & 10.583 \\
\hline$d i s^{s u b}$ & Distance to the nearest subcenter $(\mathrm{km})$ & 15.209 & 11.854 & 11.652 & 7.528 & 28.298 & 12.282 \\
\hline $\log T P_{2000}$ & $\log$ (total population density) in 2000 & 7.843 & 1.839 & 8.251 & 1.374 & 5.768 & 1.084 \\
\hline $\log L R_{2000}$ & $\log ($ local resident density) in 2000 & 7.624 & 1.827 & 7.971 & 1.412 & 5.651 & 1.069 \\
\hline $\log F P_{2000}$ & $\log$ (floating population density) in 2000 & 5.867 & 2.180 & 6.588 & 1.386 & 3.108 & 1.498 \\
\hline Motor & The private vehcle amount in every 100 people in 2010 & 19.149 & 3.572 & 18.956 & 2.686 & 16.217 & 1.062 \\
\hline \multicolumn{8}{|c|}{ Instrumental variables } \\
\hline$d i s^{s w 56}$ & Distance to the nearest subway station in 1956 plan $(\mathrm{km})$ & 13.784 & 14.371 & 7.893 & 7.187 & 33.874 & 9.406 \\
\hline $\operatorname{dis}^{e s}$ & Distance to the Euclidean spanning tree network $(\mathrm{km})$ & 7.072 & 7.872 & 4.932 & 5.151 & 12.992 & 10.658 \\
\hline \multicolumn{2}{|c|}{ Number of subdistricts } & \multicolumn{2}{|l|}{226} & \multicolumn{2}{|l|}{135} & \multicolumn{2}{|l|}{60} \\
\hline
\end{tabular}

\subsection{First-stage results}

We conduct the first-stage analysis to test the validity of the instruments. If the instruments 
are highly correlated with the transportation improvements and uncorrelated with the error term, the instruments are regarded as strong instruments. Table 4 shows that the Euclidean spanning tree network and the 1956 Beijing subway plan are both strong predictors of actual urban transit improvements in 2000-2010. Using all the exogenous covariates and these two instruments, we can predict transportation improvements. This transportation improvement predictor represents the real transportation improvements but is exogenous with the population change. With this transportation improvement predictor, the following IV estimator capture only the effects of transportation improvements on population changes and addresses the issue of endogeneity. First-stage results indicate that expressways were improved close to Euclidean spanning tree network and the subway stations in the 1956 plan, whereas contemporary subway stations were far away from them. Panel A in Table 4 shows that conditional on control variables, in the BMA one kilometer closer to Euclidean spanning tree network resulted in a 0.11 kilometer reduction of the distance to the nearest expressway ramp for total population; and one kilometer farther away from the nearest subway station in the 1956 plan resulted in a 0.19 kilometer reduction of the distance to the nearest contemporary subway station for total population. Panel B and Panel C show in the outer suburbs the estimated coefficients of the distance to the nearest expressway ramp and the distance to the nearest subway stations are around twice that as the inner suburbs. This means that the actual transportation improvements were greater in outer suburbs than that in inner suburbs, conditioning the control variables.

\subsection{Results of Two Stage Least Squares}

In this section we present estimates of the causal effects of the improvements of expressways and subways on population growth. In addition, these estimates are compared between the local residents and the floating population. In IV regression, the distance to the Euclidean spanning tree network and the distance to the nearest subway station in the 1956 plan enter as instruments for the actual improvements of expressways and subways. Comparing the TSLS results and their OLS counterparts, we find that in the BMA the TSLS estimators of transportation improvements are smaller than the OLS estimator while in the inner suburbs the TSLS estimators are larger than the OLS estimator. In the whole urban area, the OLS regression would overestimate the effects of transportation improvements on population growth because high population density areas would attract much more transportation infrastructure investment. On the contrary, in the suburban areas, the OLS regression would underestimate the effects of transportation improvements because a large number of government's transportation infrastructure investments may be placed on undeveloped areas and aim to attract population. We use three statistics: F-statistic, Wald $\chi^{2}$-statistics and $\mathrm{R}$-squared to measure the fit of the estimation model. F-statistic and Wald $\chi^{2}$-statistics are used to test the whole estimation model for the OLS regression and IV regression respectively, and R-squared is used to measure how well the estimates have explained the actual dependent variable. Except for the estimation model for the floating population in the outer suburbs, F-statistic and Wald $\chi^{2}$-statistics are statistically significant in most estimation models. This shows that the fit of most estimation models is good. The low R-squared values of most estimation models in Table 5 indicate that we could not produce reasonably precise predictions. This might be caused by the difficulty to predict human behavior, such as population spatial distribution. Therefore, despite of the low R-squared, our conclusions about 
Table 4 First-stage results of the Two-Stage Least Squares (TSLS)

\begin{tabular}{|c|c|c|c|c|c|c|c|c|}
\hline \multirow{3}{*}{ Variables } & \multicolumn{4}{|c|}{ Total population } & \multirow{2}{*}{\multicolumn{2}{|c|}{$\begin{array}{c}\text { Local residents } \\
\text { Model } 3 \\
\end{array}$}} & \multirow{2}{*}{\multicolumn{2}{|c|}{$\begin{array}{c}\text { Floating population } \\
\text { Model } 4 \\
\end{array}$}} \\
\hline & \multicolumn{2}{|c|}{ Model 1} & \multicolumn{2}{|c|}{ Model 2} & & & & \\
\hline & $\Delta\left(\operatorname{dis}^{e x p}\right)$ & $\Delta\left(d i s^{s w}\right)$ & $\Delta\left(\operatorname{dis}^{\exp }\right)$ & $\Delta\left(d i s^{s w}\right)$ & $\Delta\left(\operatorname{dis}^{\exp }\right)$ & $\Delta\left(d i s^{s w}\right)$ & $\Delta\left(\operatorname{dis}^{\exp }\right)$ & $\Delta\left(d i s^{s w}\right)$ \\
\hline \multicolumn{9}{|c|}{ Panel A: Entire BMA } \\
\hline$d i s^{e s}$ & $0.107 * * *$ & $-0.485 * * *$ & $0.110 * * *$ & $-0.477 * * *$ & $0.106^{* * *}$ & $-0.484 * * *$ & $0.112 * * *$ & $-0.460 * * *$ \\
\hline $\operatorname{dis}^{s w 56}$ & $0.652 * * *$ & $-0.190^{*}$ & $0.639 * * *$ & $-0.229 * *$ & $0.666 * * *$ & $-0.201 * *$ & $0.648 * * *$ & $-0.200 * *$ \\
\hline $\operatorname{dis}^{C B D}$ & $-0.502 * * *$ & $0.278 * * *$ & $-0.487 * * *$ & $0.323 * * *$ & $-0.506^{* * *}$ & $0.298 * * *$ & $-0.508 * * *$ & $0.218^{* * *}$ \\
\hline$d i s^{s u b}$ & $-0.404 * * *$ & $-0.235 * * *$ & $-0.399 * * *$ & $-0.219 * * *$ & $-0.406 * * *$ & $-0.224 * * *$ & $-0.410 * * *$ & $-0.280 * * *$ \\
\hline $\log P_{2000}$ & -0.088 & -0.307 & -0.128 & -0.433 & -0.118 & -0.137 & -0.175 & $-0.981 * * *$ \\
\hline Motor & & & 0.715 & $0.224 * *$ & & & & \\
\hline Constant & $4.680^{*}$ & 1.782 & 3.410 & -2.204 & $4.965^{*}$ & -0.006 & $5.272 * *$ & $7.030 * * *$ \\
\hline R-squared & 0.491 & 0.577 & 0.492 & 0.586 & 0.491 & 0.576 & 0.491 & 0.598 \\
\hline $\begin{array}{l}\text { Number of } \\
\text { subdistricts }\end{array}$ & 226 & 226 & 226 & 226 & 226 & 226 & 226 & 226 \\
\hline \multicolumn{9}{|c|}{ Panel B: Inner suburbs } \\
\hline $\operatorname{dis}^{e s}$ & 0.050 & $-0.676 * * *$ & $0.078^{*}$ & $-0.695 * * *$ & 0.050 & $-0.673^{* * *}$ & 0.036 & $-0.655 * * *$ \\
\hline$d i s^{s w 56}$ & $0.594 * * *$ & $-0.268 * *$ & $0.605 * * *$ & $-0.275^{* *}$ & $0.592 * * *$ & $-0.267 * *$ & $0.619 * * *$ & $-0.316^{* * *}$ \\
\hline $\operatorname{dis}^{C B D}$ & $-0.517 * * *$ & $0.185 * *$ & $-0.475 * * *$ & $0.157 * *$ & $-0.523 * * *$ & $0.196^{* *}$ & $-0.506^{* * *}$ & $0.143 *$ \\
\hline$d i s^{s u b}$ & $-0.271 * * *$ & -0.056 & $-0.239 * * *$ & -0.078 & $-0.277 * * *$ & -0.047 & $-0.260 * * *$ & -0.098 \\
\hline $\log P_{2000}$ & 0.224 & -0.156 & 0.368 & -0.255 & 0.143 & 0.014 & 0.444 & $-0.881 * *$ \\
\hline Motor & & & $0.313 * * *$ & -0.213 & & & & \\
\hline Constant & 1.777 & 0.983 & $-6.569 *$ & 6.663 & 2.648 & -0.479 & 0.294 & $6.869 * *$ \\
\hline R-squared & 0.545 & 0.623 & 0.580 & 0.630 & 0.544 & 0.622 & 0.550 & 0.637 \\
\hline $\begin{array}{l}\text { Number of } \\
\text { subdistricts }\end{array}$ & 135 & 135 & 135 & 135 & 135 & 135 & 135 & 135 \\
\hline \multicolumn{9}{|c|}{ Panel C: Outer suburbs } \\
\hline$d i s^{e s}$ & $0.182 * *$ & $-0.363^{* * *}$ & $0.243 * * *$ & $-0.319 * * *$ & $0.179 * *$ & $-0.368 * * *$ & $0.250 * * *$ & $-0.326 * * *$ \\
\hline$d i s^{s w t 56}$ & $1.038 * * *$ & $-0.611 * *$ & $1.415 * * *$ & -0.340 & $1.103 * * *$ & $-0.563 * *$ & $0.842 * * *$ & $-0.845 * * *$ \\
\hline $\operatorname{dis}^{C B D}$ & $-0.780 * *$ & $0.715^{* * *}$ & $-1.069 * * *$ & $0.507^{* *}$ & $-0.841 * *$ & $0.672 * * *$ & $-0.606^{* *}$ & $0.915 * * *$ \\
\hline$d i s^{s u b}$ & $-0.547 * * *$ & $-0.233 * * *$ & $-0.616^{* * *}$ & $-0.283^{* * *}$ & $-0.561 * * *$ & $-0.242 * * *$ & $-0.511 * * *$ & $-0.198 * * *$ \\
\hline $\log P_{2000}$ & -1.639 & $-2.189 * * *$ & -0.100 & $-01.730 * * *$ & $-1.835^{*}$ & $-2.296 * * *$ & $-1.109 *$ & $-1.637 * * *$ \\
\hline Motor & & & $-2.057 * *$ & $-1.477 * * *$ & & & & \\
\hline Constant & 15.335 & $6.760 * * *$ & $45.878 * * *$ & $28.691 * * *$ & 17.177 & 7.675 & 7.184 & -2.952 \\
\hline R-squared & 0.411 & 0.810 & 0.477 & 0.836 & 0.420 & 0.809 & 0.421 & 0.835 \\
\hline $\begin{array}{l}\text { Number of } \\
\text { subdistricts }\end{array}$ & 60 & 60 & 60 & 60 & 60 & 60 & 60 & 60 \\
\hline
\end{tabular}

Notes: $* p<0.10 ; * * p<0.05 ; * * * p<0.01 . \log P_{2000}$ is general designation of log population density in 2000. In Column $1-2 \log P_{2000}$ refers to $\log T P_{2000}$; in Column 3-4 $\log P_{2000}$ refers to $\log L R_{2000}$; in Column 5-6 $\log P_{2000}$ refers to $\log F P_{2000}$.

how changes in the population density changes are associated with changes in the transportation improvement are still valid.

Panel A in Table 5 shows results of the effects of the improvements of expressways and subways on population growth for the entire BMA. It indicates that only subway improvements were significantly positively associated with population growth. Although OLS results show weak negative association between expressway improvements and the growth of 
Table 5 First-difference regression of the determinants of population growth, 2000-2010

\begin{tabular}{|c|c|c|c|c|c|c|c|c|}
\hline \multirow{3}{*}{ Variables } & \multicolumn{4}{|c|}{$\Delta(\log T P)$} & \multirow{2}{*}{\multicolumn{2}{|c|}{$\frac{\Delta(\log L R)}{\text { Model } 3}$}} & \multirow{2}{*}{\multicolumn{2}{|c|}{$\begin{array}{c}\Delta(\log F P) \\
\text { Model } 4\end{array}$}} \\
\hline & \multicolumn{2}{|c|}{ Model 1} & \multicolumn{2}{|c|}{ Model 2} & & & & \\
\hline & OLS & IV & OLS & IV & OLS & IV & OLS & IV \\
\hline \multicolumn{9}{|c|}{ Panel A: Entire BMA } \\
\hline$\Delta\left(d i s^{e x p}\right)$ & 0.010 & -0.004 & $0.012 * *$ & 0.008 & 0.006 & -0.014 & $0.018 *$ & 0.036 \\
\hline$\Delta\left(d i s^{s w}\right)$ & $-0.029 * * *$ & $-0.027 * * *$ & $-0.026 * * *$ & $-0.021 * *$ & $-0.018 * * *$ & $-0.020 * *$ & $-0.045^{* * *}$ & $-0.025^{*}$ \\
\hline$d i s^{C B D}$ & $-0.025 * * *$ & $-0.025 * * *$ & $-0.028 * * *$ & $-0.028 * * *$ & $-0.013 * * *$ & $-0.013 * * *$ & $-0.050 * * *$ & $-0.049 * * *$ \\
\hline$d i s^{s u b}$ & $-0.012 * * *$ & $-0.014^{* *}$ & $-0.012 * * *$ & $-0.011 *$ & $-0.010^{* * *}$ & $-0.015^{* *}$ & -0.002 & 0.011 \\
\hline $\log P_{2000}$ & $-0.229 * * *$ & $-0.225^{* * *}$ & $-0.204 * * *$ & $-0.202 * * *$ & $-0.137 * * *$ & $-0.131 * * *$ & $-0.357^{* * *}$ & $-0.326^{* * *}$ \\
\hline Motor & & & $-0.036 * * *$ & $-0.037 * * *$ & & & & \\
\hline Constant & $2.664 * * *$ & $2.634 * * *$ & $3.217 * * *$ & $3.219 * * *$ & $1.474 * * *$ & $1.433 * * *$ & $3.917 * * *$ & $3.659 * * *$ \\
\hline R-squared & 0.354 & 0.342 & 0.388 & 0.387 & 0.204 & 0.168 & 0.385 & 0.357 \\
\hline $\mathrm{F}$ & $24.13 * * *$ & & $23.11 * * *$ & & $11.24 * * *$ & & $27.5 * * *$ & \\
\hline Wald $\chi^{2}$ & & $97.34 * * *$ & & $119.80 * * *$ & & $45.88 * * *$ & & $108.69^{* * *}$ \\
\hline $\begin{array}{l}\text { Number of } \\
\text { subdistricts }\end{array}$ & 226 & 226 & 226 & 226 & 226 & 226 & 226 & 226 \\
\hline \multicolumn{9}{|c|}{ Panel B: Inner suburbs } \\
\hline$\Delta\left(\operatorname{dis}^{\exp }\right)$ & 0.017 & -0.009 & 0.021 & -0.009 & 0.012 & -0.022 & $0.031 * *$ & 0.028 \\
\hline$\Delta\left(d i s^{s w}\right)$ & $-0.020 * *$ & $-0.033 * * *$ & $-0.019^{* *}$ & $-0.030 * *$ & -0.011 & $-0.025^{*}$ & $-0.030 * * *$ & $-0.042 * * *$ \\
\hline$d i s^{C B D}$ & $-0.023 * * *$ & $-0.029 * * *$ & $-0.026 * * *$ & $-0.032 * * *$ & -0.011 & $-0.020 * *$ & $-0.041 * * *$ & $-0.045 * * *$ \\
\hline$d i s^{s u b}$ & -0.009 & $-0.012 *$ & $-0.012 *$ & $-0.014 * *$ & $-0.012^{*}$ & $-0.016^{* *}$ & 0.007 & 0.004 \\
\hline $\log P_{2000}$ & $-0.267 * * *$ & $-0.261 * * *$ & $-0.280 * * *$ & $-0.269 * * *$ & $-0.160 * * *$ & $-0.151^{* *}$ & $-0.400 * * *$ & $-0.411 * * *$ \\
\hline Motor & & & -0.027 & -0.019 & & & & \\
\hline Constant & $3.055^{* * *}$ & $3.022 * * *$ & $3.774 * * *$ & $3.534 * * *$ & $1.761^{* * *}$ & $1.718^{* * *}$ & $4.171 * * *$ & $4.273^{* * *}$ \\
\hline R-squared & 0.332 & 0.308 & 0.346 & 0.318 & 0.163 & 0.116 & 0.444 & 0.438 \\
\hline $\mathrm{F}$ & $12.82 * * *$ & & $11.26^{* * *}$ & & $5.03 * * *$ & & $20.6 * * *$ & \\
\hline Wald $\chi^{2}$ & & $61.37 * * *$ & & $63.11^{* * *}$ & & $24.76 * * *$ & & $102.48 * * *$ \\
\hline $\begin{array}{l}\text { Number of } \\
\text { subdistricts }\end{array}$ & 135 & 135 & 135 & 135 & 135 & 135 & 135 & 135 \\
\hline \multicolumn{9}{|c|}{ Panel C: Outer suburb } \\
\hline$\Delta\left(d i s^{\exp }\right)$ & 0.008 & 0.001 & 0.008 & 0.006 & 0.006 & -0.010 & 0.028 & 0.403 \\
\hline$\Delta\left(d i s^{s w}\right)$ & -0.008 & -0.015 & 0.003 & -0.015 & -0.003 & -0.016 & -0.012 & 0.231 \\
\hline $\operatorname{dis}^{C B D}$ & $-0.010 * *$ & -0.008 & $-0.009 * *$ & -0.008 & -0.004 & 0.000 & $-0.056^{* * *}$ & -0.143 \\
\hline$d i s^{s u b}$ & 0.003 & -0.002 & 0.003 & 0.001 & 0.004 & -0.001 & 0.014 & 0.231 \\
\hline $\log P_{2000}$ & 0.057 & 0.035 & 0.063 & 0.054 & $0.067 *$ & 0.030 & $-0.159^{*}$ & 0.607 \\
\hline Motor & & & -0.015 & -0.030 & & & & \\
\hline Constant & -0.039 & 0.047 & 0.152 & 0.412 & -0.436 & -0.322 & $3.316^{* * *}$ & 2.372 \\
\hline R-squared & 0.352 & 0.317 & 0.354 & 0.346 & 0.223 & 0.001 & 0.432 & 0.001 \\
\hline $\mathrm{F}$ & $5.88 * * *$ & & $4.84 * * *$ & & $3.10 * * *$ & & $8.20 * * *$ & \\
\hline Wald $\chi^{2}$ & & $30.63 * * *$ & & $32.32 * * *$ & & $13.89 * *$ & & 4.25 \\
\hline $\begin{array}{l}\text { Number of } \\
\text { subdistricts }\end{array}$ & 60 & 60 & 60 & 60 & 60 & 60 & 60 & 60 \\
\hline
\end{tabular}


the floating population, IV results indicate this association was not statistically significant. For the total population, coefficients on the subway improvements indicate that subdistricts with greater reductions in the distance to their nearest subway stations grew more quickly. OLS results indicate that conditional on control variables, reducing the distance to the nearest subway station by one kilometer was associated with approximately $2.9 \%$ population growth. IV estimates imply roughly a $2.7 \%$ population growth for each kilometer reduced to the nearest subway station. In respect to the social group differences, the greater effect of the subway improvements was on the floating population. OLS results indicate that conditional on control variables, reducing access by one kilometer to the nearest subway station was associated with a $4.5 \%$ increase in the floating population, while IV estimates imply a $2.5 \%$ increase in the floating population by reducing each kilometer to the nearest subway station. This implies that urban subway system had more appealing to the floating population than the local residents. It is mainly caused by the rather low fare of urban subway system. Beijing's subway had been one of the world's cheapest because of a massive government subsidy during 2000 and 2010. This could result in excessive floating population growth and residential segregation between the local residents and the floating population. First, the rather low fare largely cut down the travel cost and mitigated the floating population's living pressure unnaturally in Beijing. This might attract more floating population to migrate into Beijing and aggregate excessive population growth. Secondly, the low fare of urban subway system attracts massive floating population to living near the subway stations and might result in residential segregation. Residential segregation hampers the floating population's economic progress and goes against urban economic sustainability through negative neighborhood effects, spatial mismatch between jobs and residents, and shortage of education, health care, medical treatment services. Columns 3 and 4 in Table 5 is the results of considering the motorization rate for the total population. It shows that expressway improvements still had no significant effects on the population growth in all the three zones conditioning the motorization rate. The reason is the low motorization rate in the suburbs where a large amount of new expressways were constructed in 2000-2010. The motorization rate declined away from CBD. The population growth in the suburbs had limited response to the expressway improvements due to the low motorization rate. As for the group differences in the motorization rate, the floating population were facing many institutional limitations on car purchasing due to hukou system. This would result in the less response to the expressway improvements for the floating population conditioning on the motorization rate.

Panel B and Panel C in Table 5 show the regional differences of the impact of the transportation on the population growth. The results show that subway improvements had significantly positive effects on population growth in the inner suburbs, not in the outer suburbs. This coincides with the convergence of the subway system in the BMA. The subways were constructed within 6th Ring Road and had not been extended to the outer suburbs. For the total population, OLS results indicate that conditional on control variables reducing access to the nearest subway station by one kilometer was associated with a population growth of $2 \%$. IV estimates imply about a $3.3 \%$ population growth by reducing each kilometer of access to the nearest subway station. The group differences of the effects of the subway improvements in the inner suburbs were significant. The subway improvements were significantly positively associated with the growth of the floating population, while it just had a 
weakly significant effect on the growth of the local residents. For the floating population OLS estimates imply a $3 \%$ population growth in the inner suburbs by reducing each kilometer of access to the nearest subway station; whereas, IV variable estimates indicate a $4.2 \%$ population growth by reducing each kilometer of access to the nearest subway station. The weakly significant association between the subway improvements and the local resident growth in the inner suburbs implies that the local residents moved to the inner suburbs not because of the increased transportation accessibility, but rather other factors, for example, urban renewal, factory suburbanization, and low-cost affordable housing construction.

The other finding in Table 5 is that the expressway improvements did not have a statistically significant impact on the population growth of either the inner suburbs or the outer suburbs. This is in contrast to previous research done in western developed countries and also contradicts the original intention of building expressways in the BMA (Baum-Snow, 2007; Garcia-López, 2012). The Beijing municipal government expects that expressways can induce the population in the city center to move to the outer suburbs, which would promote the urban polycentric development of the BMA. However, the causal effects of expressway improvements contradicted its original intention. It is mainly resulted from differences of the population composition and the motorization rate in the suburban areas between China and western countries. Most new expressways were constructed in the suburban areas in the BMA in 2000-2010. But in these areas the floating population accounted for the majority group and they had less access to private vehicles. This resulted in the fact that the population growth had limited response to the expressway improvements due to the low motorization rate. In western countries, highways give rise to suburbanization and the affluent population move to suburban areas to seek better living condition with the popularity of private vehicles. However, the living condition of suburban areas in China is not as desirable as western countries (Zhao, 2011). This cause the affluent people are willing to reside close to the city center. The suburbanization in Chinese city came mainly from the urban renewal, industry spatial restructuring and low-cost affordable housing construction, which involve mainly the socio-economic disadvantaged people. These disadvantaged people largely rely on public transportation rather than private vehicles (Chen and Cai, 1996; Gao and Jiang, 2002). Therefore, expressway improvements were not an incentive of suburbanization and did not significantly affect population redistribution in metropolitan areas in China.

\section{Conclusions and discussion}

This study analyzes the spatial redistribution of population in the BMA between 2000 and 2010 and estimates the causal effects of urban transportation improvements on population spatial redistribution, focusing on the group differences between the local residents and the floating population. Due to the endogeneity of transportation improvement and population growth, IV regression model is applied to avoid this problem, and then to estimate the extent to which urban transportation improvement had casual effects on population growth across the BMA. We find that:

Firstly, the BMA was at a suburbanization stage between 2000 and 2010, which refers total population density decreased in the city center but increased in the inner suburbs. This finding is consistent with previous suburbanization studies in Beijing ( $\mathrm{Hu}$ and Foggin, 1994; 
Zhou, 1996). In addition, we find that Beijing's suburbanization was mostly attributed to the local residents rather than the floating population, which is always neglected by urban researchers.

Secondly, IV regression results verified that urban transportation improvements had significantly effects on population redistribution in the BMA. However, the regional studies show this association was not applicable for the local residents in the inner suburbs. It indicates that suburbanization in the BMA was not driven by the extension of UTS. This conclusion contradicts previous suburbanization studies in China, which states that transportation accessibility improvements were an incentive for people to move to suburban areas.

Thirdly, the positive effects of transportation improvements on population growth just occurred in inner suburbs, not in outer suburbs. This is related to the insignificant association of expressway improvement with population growth. This finding is different from the research on cities in western countries. It is mainly resulted from differences of the population composition in the suburban areas between China and western countries. The majority group is the floating population in the suburban areas of China, who rely mostly on public transportation; whereas the affluent people is the largest group in the suburban areas of western countries, who have more access to private vehicle.

These findings have considerable implications in the decision-making process of urban planning and management. Firstly, urban transportation accessibility improvement can be utilized as an essential tool in the process of pursuing reasonable redistribution of urban population for the urban planners and authorities. Secondly, the effects of urban transportation improvements on population growth should be assessed scientifically. It is given too little attention to that the extension of UTS had limited effects on inducing population moving to suburban areas and controlling center city's population under the present circumstances in China. In other words, urban transportation improvements gave rise to the population growth in suburban areas, but did not induce people to move from city center to suburban areas in the big cities in China. Thirdly, it is urgently needed to improve urban public transportation accessibility in the suburban areas, especially in the outer suburbs. This is an essential step to achieve floating population equalization of basic services and prompt the floating population to integrate into local society. Moreover, it is necessary to plan and design reasonable and scientific UTS in order to control excessive population growth and promote residential integration. And residential integration would advance the floating population's economic progress and urban competitiveness increasing. Even though it can mitigate traffic congestion and reduce automobile gas emission, the excessive subsidy on urban public transportation may aggregate heavy population pressure and residential differentiation in the BMA. Therefore, it should be considered and evaluated the dual effects of urban public transportation on urban sustainability development.

\section{Acknowledgments}

We thank Prof. Michael J. White in Brown University for the comments and suggestions on this research. We also thank the Writing Center in Brown University, Joan and John Kenower for the language revision. 


\section{References}

Alonso W, 1964. Location and Land Use. MA, USA Harvard University Press.

Anas A, Mosesm L N, 1979. Mode choice, transport structure, and urban land use. Journal of Urban Economics, 6(2): 228-246.

Arnott R J, McMillen D P, 2008. A Companion to Urban Economics. Blackwell: Oxford, UK.

Baum-Snow N, 2007. Did highways cause suburbanization? The Quarterly Journal of Economics, 122(12): 775-805.

Beckmann M J, 1969. On the distribution of urban rent and residential density. Journal of Economic Theory, 1(1): 60-67.

Brezzi M, Veneri P, 2014 Assessing polycentric urban systems in the OECD: Country, regional and metropolitan perspectives. European Planning Studies, 23(6): 1128-1145.

Calvo F, Oña J D, Arán F, 2013. Impact of the Madrid subway on population settlement and land use. Land Use Policy, 31(2): 627-639.

Chi G, 2012. The impacts of transport accessibility on population change across rural, suburban, and urban areas: A case study of Wisconsin at subcounty levels. Urban Studies, 49(12): 2711-2731.

Clark C, 1951. Urban population densities. Journal of the Royal Statistical Society, 114(4): 490-496.

Duranton G, Turner M A, 2008. Urban growth and transportation. Review of Economic Studies, 79(4): 1407-1440.

Feng J, Wang F, Zhou Y, 2013. The spatial restructuring of population in metropolitan Beijing: Toward polycentricity in the post-reform era. Urban Geography, 30(7): 779-802. (in Chinese)

Feng J, Zhou Y, 2008. Restructuring of socio-spatial differentiation in Beijing in the Transition Period. Acta Geographica Sinica, 63(8): 829-844. (in Chinese)

Fujita M, Ogawa H, 1982. Multiple equilibria and structural transition of non-monocentric urban configurations. Regional Science and Urban Economics, 12(82): 161-196.

Garcia-López M, 2012. Urban spatial structure, suburbanization and transportation in Barcelona. Journal of Urban Economics, 72(S2/3): 176-190.

Garreau J, 1991. Edge City: Life on the New Frontier. New York, USA: Doubleday.

Glaeser E L, Kahn M E, Rappaport J, 2008. Why do the poor live in cities? The role of public transportation. Journal of Urban Economics, 63: 1-24.

Hashimoto S, Taniguchi M, Matsunaka R, 2009. Relation of public transportation service level and city diffusion by area based population density. Journal of the City Planning Institute of Japan, 44: 117-123.

He S, 2010. New-build gentrification in central Shanghai: Demographic changes and socioeconomic implications. Population, Space and Place, 16(5): 345-361.

Huang Y, Jiang L, 2009. Housing inequality in transitional Beijing. International Journal of Urban and Regional Research, 33(4): 936-956.

Ji W, Wang Y, Zhuang D et al., 2014. Spatial and temporal distribution of expressway and its relationships to land cover and population: A case study of Beijing, China. Transportation Research Part D Transport \& Environment, 32: 86-96.

Logan J R, 2008. Chapter 14. Temporary Migrants in Shanghai: Housing and Settlement Patterns. The New Chinese City: Globalization and Market Reform. Blackwell Publishers Ltd.

Logan J R, Fang Y, Zhang Z, 2009 Access to housing in urban China. International Journal of Urban \& Regional Research, 33(4): 914-935.

Kim D S, 2007. Location modeling of population and land-use change in rural area by new expressway. Journal of Urban Planning \& Development, 133(3): 201-210.

Kotavaara O, Antikainen H, Mathieu M et al., 2012. Scale in the effect of accessibility on population change: GIS and a statistical approach to road, air and rail accessibility in Finland, 1990-2008. Geographical Journal, 178(4): 366-382.

Kotavaara O, Antikainen H, Rusanen J, 2011. Population change and accessibility by road and rail networks: GIS and statistical approach to Finland 1970-2007. Journal of Transport Geography, 19(4): 926-935. 
Lau C Y, 2011 Spatial mismatch and the affordability of public transport for the poor in Singapore's new towns. Cities, 28(3): 230-237.

Li Z, Wu F, 2006. Socio-spatial differentiation in transitional Shanghai. Acta Geographica Sinica, 61(2): 199-211. (in Chinese)

Liu R, 2015. Spatial Mobility of Migrant Workers in Beijing, China. London: Springer.

Liu S, Zhao M, Qi W, 2014. The floating population and its spatial impacts. In: Dunford M, Liu W (eds). The Geographical Transformation of China. Oxon, UK: Routledge.

Ma Q, Zhang W, 2006 Characteristics and factors analyses of suburbanization in Beijing. Geographical Research, 25(1): 121-130. (in Chinese)

McDonald J F, 1989. Econometric studies of urban population density: A survey. Journal of Urban Economics, 26(3): 361-385.

Meyer J R, Gómez-Ibáñez J A, 1981. Autos, Transit, and Cities. Harvard University Press: MA, USA.

Mills E S, 1967. An aggregative model of resource allocation in a metropolitan area. The American Economic Review, 57(2): 197-210.

Muller P O, 1981. Contemporary Suburban America. Prentice Hall: New Jersey, USA.

Muth R F, 1969. Cities and Housing. Chicago, USA: University of Chicago Press.

Preston V, McLafferty S, Hamilton E, 2013. The impact of family status on black, white, and hispanic women's commuting. Urban Geography, 14(3): 228-250.

Qin Y, Du W, 2000. The effect of urban rail transportation on the urban structure. Journal of Southwest Jiaotong University, 35: 284-285. (in Chinese)

Rogalsky J, 2013. Bartering for basics: Using ethnography and travel diaries to understand transportation constraints and social networks among working-poor women. Urban Geography, 31(31): 1018-1038.

Starrs M, Perrins C, 1989. The markets for public transport: The poor and the transport disadvantaged. Transport Reviews, 9(1): 59-74.

Sun T, Wang L, Li G, 2012. Distribution of population and employment and evolution of spatial structures in the Beijing Metropolitan Area. Acta Geographica Sinica, 67(6): 829-840. (in Chinese)

Sun Y, 1992. Forming mechanism and delimitation of metropolitan area in China: A case study of Beijing. Acta Geographica Sinica, 47(6): 552-560. (in Chinese)

Sweet M N, Bullivant B, Kanaroglou P S, 2016. Are major Canadian city-regions monocentric, polycentric, or dispersed? Urban Geography: 1-27.

Veneri P, 2010. Urban polycentricity and the costs of commuting: Evidence from Italian metropolitan areas. Growth \& Change, 41(3): 403-429.

Wang Y, Wang Y, Wu J, 2010. Housing migrant workers in rapidly urbanizing regions: A study of the Chinese model in Shenzhen. Housing Studies, 25(1): 83-100. (in Chinese)

Wu J, Li R, Ding R et al., 2017. City expansion model based on population diffusion and road growth. Applied Mathematical Modelling, 43: 1-14.

Wu Q, Wu X, Chen G et al., 2013. Social-spatial differentiation and residential segregation of old city of Nanjing, China: Evidence from the community-level census data in 2000. Scientia Geographica Sinica, 33(10): 1196-1205. (in Chinese)

$\mathrm{Wu}$ W, 2008. Migrant settlement and spatial distribution in metropolitan Shanghai. The Professional Geographer, 60(1): 101-120.

Zeng Z, Lin F, 2005. The effect of urban rail transition on population migration. Urban Mass Transit, 8(2): 19-22. (in Chinese) 